\title{
Editorial
}

\section{Introduction and Editorial to the Special Issue "Selected Papers from the Building a Better New Zealand (BBNZ 2014) Conference"}

\section{George Baird}

School of Architecture, Victoria University of Wellington, PO Box 600, Wellington 6140, New Zealand; E-Mail: george.baird@vuw.ac.nz; Tel.: +64 4463 6231; Fax: +64 44636204

Academic Editor: Chimay Anumba

Received: 16 April 2015 / Accepted: 22 April 2015 / Published: 24 April 2015

\section{The Background to the Conference}

The current "Building a Better New Zealand" initiative began in 2009 with the New Zealand Government and the Building Industry working together to develop "Building the Future"-a document that looked at the challenges and opportunities facing the country's building and construction industry in coming decades.

That document made the need for an "overarching building and construction research strategy" very clear. It was recognised that a successful and innovative building industry would be critical if the country was to provide the homes, workplaces and communities that would secure firm foundations for its future. The country also faced the distinct challenges and opportunities of rebuilding the city of Christchurch, following the devastating earthquake of 2011; and coping with a projected $40 \%$ increase in the population of its largest city, Auckland, over the next 25 years.

Thus it was, following extensive consultation with government and industry during 2012, that a Building a Better New Zealand Research Strategy Document was developed jointly by the Building Research Association of New Zealand, the Construction Industry Council, and the Ministry of Business Innovation and Employment. Its publication in June 2013 provided the incentive and inspiration for the organising committee of what became known as the Building a Better New Zealand Conference (BBNZ 2014) that was held in Auckland from 3 to 5 September 2014 and was planned around the following themes:

- Achieving better buildings;

- Improving the performance of materials;

- Improving the performance of existing buildings; 
- Sustainability;

- Productivity;

- Meeting New Zealanders housing needs;

- $\quad$ Building better cities and communities.

Deliberately geared to provide a forum for researchers and industry, the conference accepted some 55 academic papers and around 45 industry presentations, covering the seven main themes, as well as a number from keynote speakers. These had been subjected to blind peer reviewing by the Conference Scientific Committee chaired by Professor George Baird, thus ensuring high quality papers and presentations. Full details of the Research Strategy Document, the Industry Needs Survey that preceded it, and the Building a Better New Zealand Conference itself may be found at the following website: http://www.buildingabetternewzealand.co.nz.

As a member of the Editorial Board of Buildings, Professor Baird explored the possibility of having a Special Issue of the journal, made up of around ten Selected Papers. His proposal was readily accepted and the authors of the academic papers most highly ranked in the conference peer review process were invited to develop their papers further and submit them to the Journal's rigorous review process.

In the event, twelve papers were accepted and form the content of this Special Issue and while the original conference papers tended to have a New Zealand focus, most authors have looked at the international applicability of their findings in these revised and expanded journal articles if they had not already done so.

\section{Content of the Special Issue}

While the selected papers were nominally spread across all of the conference themes, with "Achieving Better Buildings" and "Productivity" the most popular, in practice most papers covered more than one theme. For the purposes of this editorial they are grouped under these two headings and a third I have labelled "Urban Issues".

\subsection{Achieving Better Buildings}

Papers by Boulic et al. [1], Birchmore et al. [2], Leardini and Manfredini [3], Bassett and Overton [4], and Cory et al. [5] make up this group. Their predominant focus is on achieving better conditions in domestic buildings.

As noted by Leardini and Manfredini of the School of Architecture and Planning at Auckland University, while much of New Zealand's housing stock is soundly constructed, many homes are uninsulated, with all the attendant problems that follow. They describe the results of a study of different retrofit upgrade packages to a section of the Auckland housing stock, concluding that "nearly zero-energy buildings .... can be achieved through retrofitting interventions that meet the EnerPHit standard" [3].

Birchmore, Pivac, and Tait from the Departments of Construction and of Building Technology at Auckland's Unitec Institute of Technology carried out full scale testing of an innovative construction 
method. This involved the use of a vapour check and a plywood barrier, and resulted in improved thermal resistance, reduced infiltration, and less risk of interstitial condensation [2].

Boulic et al. [1] evaluated mould growth in the living rooms and bedrooms of two sets of occupied houses, one set with unflued gas heaters, the other with electric heat pumps. Perhaps unsurprisingly, the unflued gas heaters were found to be a significant additional source of moisture, and the houses in which they were fitted had average daily hyphal growth rates several times higher than the houses fitted with the heat pumps.

Bassett and Overton of the Building Research Association of New Zealand investigated the performance of three different forms of flashing under dynamic wind and rain loads. All three were found to resist water leakage, but the influence of vents and other air leakage paths remains to be studied [4].

The final paper in this group, by Cory, Donn, and Pollard of the Centre for Building Performance Research at Victoria University of Wellington's School of Architecture and the Building Research Association of New Zealand aims to make the energy modelling of commercial buildings much more realistic. Using data from a national building energy end-use study, the authors present typical, high, and low energy load densities and their operational patterns for commercial buildings [5].

\subsection{Productivity}

These four papers by Shahzad et al. [6]; Zhang et al. [7], Noktehdan et al. [8] and Antunes and Gonzales [9], all deal with matters related to construction industry productivity.

Shahzad, Mbachu and Domingo from the School of Engineering and Advanced Technology at Massey University in Auckland analysed 66 Auckland building projects where prefabrication had been employed to assess productivity differences from traditional building systems. They found that prefabrication resulted in average reductions in completion times and costs of 34\% and 19\% respectively. This translated to an overall average productivity improvement of $7 \%$, with housing the most improved at $11 \%$ [6].

In their contribution, Noktehdan, Shahbazpour and Wilkinson from the Departments of Civil and Environmental Engineering and of Mechanical Engineering at the University of Auckland examine the relationship between innovation and productivity improvement in the construction industry. Having developed an innovation classification system they go on to demonstrate it via a database of 500 innovations, and proposing its use for calculating innovation performance indicators [8].

Antunes and Gonzales, also from the School of Civil and Environmental Engineering at the University of Auckland, set out to examine existing knowledge about production models in order to establish a foundation for dynamic production systems management in construction, proposing a theoretical framework for the future development of mathematical production models aimed at predicting performance [9].

No discussion of productivity would be complete without the topic of Building Information Modelling (BIM). In their paper, Zhang, Seet and Lie from the Department of Electrical and Electronic Engineering at Auckland University of Technology investigate how BIM can contribute to the development of Smart Built Environments from the design phase to facility management [7]. 


\subsection{Urban Issues}

Papers by Allen [10], Gjerde and Vale [11] and Nouri [12] deal with a variety of important urban issues.

Allen from the School of Architecture and Planning at the University of Auckland is concerned with the role that urban amenities play in providing a sense of liveability for the residents of a neighbourhood. Based on the results of 57 face-to-face interviews in four Auckland suburbs, insights were gained into the trade-offs residents were prepared to make when choosing to live in medium-density housing typologies [10].

Gjerde and Vale from the School of Architecture at Victoria University of Wellington investigated the effectiveness of design review systems in ensuring the visual quality of streetscapes. Results of a case study of a Wellington street are presented and the authors speculate how such systems could be made to work more effectively [11].

Additionally, concerned with the urban realm, Nouri from the Faculty of Architecture at the University of Lisbon addresses the issue of thermal comfort in public spaces. Following an extensive international review the author develops a framework of relevant bioclimatic case studies, arguing that there is sufficient existing knowledge to respond to the growing need for thermal comfort attenuation in the city of Auckland [12].

\section{Acknowledgments}

Finally, it is my pleasure to thank my Co-Guest Editors Lois Easton and Adrian Bennett for their assistance, the reviewers for their exacting commentaries and suggestions, all the authors for responding to these with alacrity, and of course the team at MDPI for facilitating this Special Issue so efficiently.

As a last word, it is gratifying to note that four of the selected papers were from $\mathrm{PhD}$ candidates, all of whom received a student award at the Conference-auguring well for future research towards the building of a better New Zealand.

\section{Conflicts of Interest}

The author declares no conflict of interest.

\section{References}

1. Boulic, M.; Phipps, R.A.; Cunningham, M.; Cleland, D.J.; Fjällström, P.; Abe, K.; Howden-Chapman, P. Heater Choice, Dampness and Mould Growth in 26 New Zealand Homes: A Study of Propensity for Mould Growth Using Encapsulated Fungal Spores. Buildings 2015, 5, 149-162.

2. Birchmore, R.; Pivac, A.; Tait, R. Impacts of an Innovative Residential Construction Method on Internal Conditions. Buildings 2015, 5, 179-195.

3. Leardini, P.; Manfredini, M. Modern Housing Retrofit: Assessment of Upgrade Packages to EnerPHit Standard for 1940-1960 State Houses in Auckland. Buildings 2015, 5, 229-251. 
4. Bassett, M.; Overton, G. Measuring the Weathertight Performance of Flashings. Buildings 2015, $5,130-148$.

5. Cory, S.; Donn, M.; Pollard, A.; Comparison of NZ's Energy Efficiency Regulation and Verification Assumptions to Real Building Loads and Operation. Buildings 2015, 5, 116-129.

6. Shahzad, W.; Mbachu, J.; Domingo, N. Marginal Productivity Gained Through Prefabrication: Case Studies of Building Projects in Auckland. Buildings 2015, 5, 196-208.

7. Zhang, J.; Seet, B.-C.; Lie, T.T. Building Information Modelling for Smart Built Environments. Buildings 2015, 5, 100-115.

8. Noktehdan, M.; Shahbazpour, M.; Wilkinson, S. Driving Innovative Thinking in the New Zealand Construction Industry. Buildings 2015, 5, 297-309.

9. Antunes, R.; Gonzalez, V. A Production Model for Construction: A Theoretical Framework. Buildings 2015, 5, 209-228.

10. Allen, N. Understanding the Importance of Urban Amenities: A Case Study from Auckland. Buildings 2015, 5, 85-99.

11. Gjerde, M.; Vale, B. Aiming for a Better Public Realm: Gauging the Effectiveness of Design Control Methods in Wellington, New Zealand. Buildings 2015, 5, 69-84.

12. Nouri, A.S. A Framework of Thermal Sensitive Urban Design Benchmarks: Potentiating the Longevity of Auckland's Public Realm. Buildings 2015, 5, 252-281.

(C) 2015 by the author; licensee MDPI, Basel, Switzerland. This article is an open access article distributed under the terms and conditions of the Creative Commons Attribution license (http://creativecommons.org/licenses/by/4.0/). 